\title{
Knowledge and Beliefs about Ebola Virus Disease (EVD) among Teachers in Ondo State Nigeria
}

\author{
Femi Rufus Tinuola, PhD \\ Email: adufem2000@yahoo.com
}

Doi:10.5901/mjss.2016.v7n3p451

\begin{abstract}
This study examines teachers' knowledge and beliefs about EVD. This study was conducted in selected secondary and primary schools in Nigeria. Data were obtained from 350 Teachers sampled randomly from Ikare (200) and Akungba (150) respectively. Fifty Teachers (30 Senior Teachers and 20 Junior Teachers) were selected from the seven schools making a grand total of 350 Teachers for the entire study. The instrument, graduated ended questions on demographic characteristics, knowledge, and beliefs about Ebola Virus Disease. The instrument was validated by a group of experts in Epidemiology, Demography and Medical Sociology in three universities. Out of 350 instruments administered, the Return-Rate at $88.6 \%$ (310) was reliable enough for the study population. During a Pre-test, a reliability value of 0.98 were collated, edited and with the use of SPSS Version 17. Findings show that the knowledge about EVD was relatively high and those different beliefs systems determine and influence the perceived health seeking behaviour. The need to under study health belief system of the people and incorporate them into the care and cure system is recommended for EVD, an epidemic too soon to be forgotten.
\end{abstract}

Keywords: Ebola, Epidemics, death, beliefs, health

\section{Introduction}

\subsection{Background}

The first global case of EVD was reported in the Democratic Republic of Congo in 1976 with high fatalities resulting from its endemic (m.allafrica.com). It spread to Uganda, Sudan \& Gabon and until recently when some cases were reported in the West African Sub-region. Specifically, the infection was traceable to a two-year old child. Due to the high contagious nature of the virus, the infection was reported in Liberia, and Sierra Leone, the neighbours of Guinea (www.who.int). The outbreak remains the largest ever documented in global history of the epidemic and the most severe acute public health emergency in recent times (World Health Organization, 2014a)

According to WHO (2014b), the global medical statistics indicate that from the first case identified in 1976 to the pre-West Africa epidemic, about 1,716 cases were confirmed while the statistics as at February 2015 sky-rocketed to 23,217 suspected cases and 9,353 deaths with a possibility of the figures being underestimated. The developed nation had their infection cases as reported in the United States, even though the travel history of the victims indicated that they were in one of the EVD endemic West African countries few days before they were diagnosed of the infection.

The first index case of Ebola was reported in July 20, 2014 through an American-Liberian Patrick Sawyer who came into Nigeria through the Murtala Mohammed International Airport, Lagos. Unfortunately, the illness behavior manifested at the point of entry and was quickly rushed to a private hospital for medical attention. Patrick Sawyer later died of complications arising from Ebola infection five days after he was diagnosed. It was obvious that Nigerians forgot their differences in cultural and ethnical backgrounds and other socio-political differences but united to fight the common enemy. The addition of 19 EVD cases discovered in Lagos and Port Harcourt were those who had primary contracts with the first index case. Significant to note in the trend of EVD infection, is that about half of the infected were the medical officers involved in the treatment of the first index case. Of course, the medical doctor and nurses who attended to Patrick Sawyer at the First Consultant Hospital, Lagos were infected and later died of the complications (Azuzu, 2014).

Only 19 of those primary contacts were diagnosed of EVD out of which $7(37 \%)$ died and $12(63 \%)$ recovered fully and discharged. Apart from Lagos where the Liberian importer of the disease landed, primary contacts travelled to Enugu and Port Harcourt without permission from medical personnel attending to them. All the 340 tertiary or quaternary contacts were under surveillance for 21 days and were later declared free of the virus by Laboratory tests and clinical signs ((Azuzu, 2014). The success fight against EVD resulted from the unity of purpose, collaboration across national, 
state, local governments, individual and groups as well as international agencies. The morbidity of EVD has increased the national and global financial burden on the global economy putting more pressures on the already over-stressed existing health infrastructures most especially in Sub -Saharan African countries where the infection was reported in epidemic proportion. On the 24th October 2014, the European Union appointed Christos Stylianides, EU Commissioner Humanitarian Aid and Crisis Management as EU Ebola coordinator. The EU total financial contribution to fight Ebola in West Africa was over 1.2 billion Euros as at February 2015 (http://ec.europa.eu/echo)

Though, Nigeria has been declared free of EVD, following a clean bill of health issued by the World Health Organisation, the response of the health sector has left us with fresh memories of the role of traditional cure system perceived intervention. For example, at the peak of the infection, came the online message allegedly linked to a traditional ruler in Igala Kingdom in Kogi State Nigeria that bathing with salted-water at the midnight would prevent infection with EVD. Probably, because of the fear of death and the respect that Nigerians have for the traditional institution, the acclaimed source of the information, most people reportedly bathed with the salted-water, not minding the negative health implications. The mystery of the salted-water therapy may require socio-philosophical investigations and explanations in the celestial world since there is no scientific basis and confirmation of the efficacy of the therapy. Shortly after, the belief that Bitter kola could cure EVD was propagated. During this period, those who were in the business of Bitter Kola recorded higher sales due to high patronage from members of the public. Professor Iwu, a Pharmacologist, who participated in the research on Bitter Kola in a Study Group sponsored by the United States Government, refuted the claim. Many so-called men of God claimed to possess some quantities of holy water that could cure EVD. In all these, the federal government using print and electronic media cautioned members of the public against these beliefs and patronizing these sources of cure but advised that all suspected cases be reported at a public health infrastructure nearest to them for medical attention.

Health education and the socio-cultural research about EVD will assist in propagating adequate knowledge about the disease. Resumptions in formal primary and secondary schools in Nigeria in 2014 were postponed to forestall continuing spread of the virus because students are acclaimed to be more vulnerable. This raises questions about the role of the school system and the teachers' knowledge about EVD and their ability to impart the knowledge on the pupils. This may guide against the re-occurrence of the epidemic that may be too soon to forget. The main thrust of this study is to examine knowledge of teachers about EVD and the implications on the knowledge imparted on the pupils about Ebola.

\subsection{Research Questions}

1. Are teachers' knowledgeable about EVD?

2. What are teachers' beliefs about the mid-night-salt water preventive therapy?

3. What is the attitude of teachers towards bitter-kola therapy?

\subsection{Research Objectives}

1. To examine teacher's knowledge about EVD

2. To determine teacher's beliefs about the mid-night -salt water preventive therapy?

3. To describe the attitude of teachers towards bitter-kola therapy?

\subsection{Significance of the study}

Since the discovery of EVD in the West African sub-region, what has surfaced is the duo challenge of managing the infected and curtailing its further spread. The on-going global, regional and national efforts at curtailing further spread and the management of those infected will be boosted by adequate knowledge of the symptoms, transmission modes and management of the disease by the people. Since most of the modes of transmission of EVD are largely behavioural, it is of sociological import to investigate the people's knowledge, \& beliefs which determine the morbidity and health behavioural patterns to the virus. Findings from this study will assist all stake-holders in population health involved in EVD management issues in incorporating the socio-behavioural dimension of the morbidity with the scientific efforts at developing a comprehensive and holistic approach to curtailing EVD in West Africa and other parts of the world. It will add to the data base on the sociology of EVD in Africa. 


\section{Research Methods}

This research was carried out using systematic sampling technique; all the communities were listed based on their demographic significance. Demographic significance, in the context of this study, is defined as the total number of people resident in the area and the frequency of basic reproductive activities. Data from the National Population Commission (2006) indicates that Ikare-Akoko and Akungba-Akoko communities have the highest demographic significance in serial order from where this study drew respondents. The respondents were teachers in formal schools (Primary and Secondary).

Data were obtained from 350 teachers simple randomly selected from lkare (200) and Akungba (150) respectively. Two Grade A Secondary Schools were selected from each of Ikare and Akungba making a total of Four Grade A Schools while two Grade B Secondary Schools were selected from Ikare and one from Akungba. Fifty teachers (30 Senior Teachers and 20 Junior Teachers) were sampled from each of the seven (7) selected schools making a grand total of 350 teachers for the entire study. The instrument, a Structured Formal Questionnaire, self- administered, contained ended questions on various issues on Ebola Virus Disease. It contains sections such as Demographic Characteristics, Knowledge, Attitude and Practices related to Ebola Virus Disease. The instrument was validated by a group of experts in Epidemiology, Demography and Medical Sociology in two Public Universities. Out of 350 instruments administered, only 310 questionnaires were retrieved putting the Return-Rate at $88.6 \%$, which was statistically reliable enough to analyse for the study population. During a Pre-test, a reliability value of 0.98 were collated, edited and analysed with the use of SPSS Version 17 . Findings were presented in descriptive statistics using frequency tables.

\section{Findings}

Data obtained were analysed and presented under different sub-heads to unveil salient issues raised towards addressing the research questions. The 310 questionnaires returned by the sampled population form the basis for this analysis.

\subsection{Characteristics of Selected Teachers}

Data indicate the basic characteristics of the selected teachers as follows: Sex: Male (44.8\%), Female (55.2\%); Education: National Certificate of Education (58\%), Higher National Diploma (12\%), B.Sc/B.Ed (26\%) and Postgraduate (4\%); Age: $<45$ years $(86.5 \%), 45$ years and above (13.5\%); Marital Status: Single $(33.9 \%)$, Ever married $(66.1 \%)$; Religion: Christianity (79.4\%), Islam (20\%) and African Traditional Religion (0.6\%).

\subsection{Ever heard about Ebola?}

More often than not, the world media report on both the electronic and print platforms on EVD shows that the disease has claimed lives of significant proportion of the people in areas where it has been reported. A common misconception in the news content is the version that portrayed EVD as a new disease, even though it was reported in some countries long ago. In the wake of re-appearing of the new infections with EVD in some countries in West Africa, severe and complicated morbidity arising from EVD as at November 2014, were estimated at about 13,268 cases out which 4000 people died. Though EVD was first discovered in 1976, in Democratic Republic of Congo, the new discoveries in Sierra Leone, Guinea and Liberia have attracted more fatalities in morbidity and mortality than ever before. In this survey, almost all the respondents (95.8\%) reported that they have heard about the Ebola virus. Knowledge about a disease is one of the major determinants of the attitude and behaviour towards the morbidity, disease progress, and the related health seeking behaviour. The publicity given to EVD resulted from its fatality and the non-existence of the major treatment, in addition to its highly contagious nature.

Table 1: Ever Heard about EVD?

\begin{tabular}{|c|c|c|}
\hline Responses & Frequency & Percentage \\
\hline Yes & 297 & 95.8 \\
\hline No & 013 & 04.2 \\
\hline Total & 310 & 100.0 \\
\hline
\end{tabular}

Source: Author's Field Survey, 2015 


\subsection{Sources of first Information about Ebola}

Those who reportedly heard about Ebola were asked to indicate their initial sources of information in tripartite classification: primary, secondary and tertiary levels. These classifications were based on the levels and agents of socialisation. Data in the Table 2 below revealed that only $5.1 \%$ got information from primary source (family) indicating agents such as parents and siblings while $10.8 \%$ got the information from secondary sources such as formal schools $(4.5 \%)$, hospitals (1.7\%), friends (1.5\%) and religious houses (1.9\%). However, majority of the sample (84.1\%) got the first information on EVD from tertiary sources such as print media (19.7\%), Facebook (30.6\%) and other electronic media (33.9\%). In summary, greater than half (53.9\%) got the information from social media as shown in Table 2.

Table 2: Sources of first Information about EVD

\begin{tabular}{|l|c|c|}
\hline Sources & Frequency & Percentage \\
\hline Primary & 15 & 5.1 \\
\hline Secondary & 32 & 10.8 \\
\hline Tertiary & 250 & 84.1 \\
\hline Total & 297 & 100.0 \\
\hline
\end{tabular}

Source: Author's Field Survey, 2015

Of recent, the social media has been identified as one of the most frequently used and fastest means of communication among the people. With the introduction of Global System of Mobile (GSM) communication network in Nigeria, recent reports indicate that $70 \%$ of the Nigeria population have access to GSM.

\subsection{Year of First Information about Ebola}

The recent re-appearance and great onslaught on the population of some countries in West Africa (Sierra Leone, Liberia, Guinea and Nigeria) has sparked off wide popularity for the virus in the region. Participants in this study were asked to indicate their year of first information on Ebola. About three-quarters of the total sample reportedly heard about Ebola between 1-2 years ago. In 2013, new cases of EVD were identified in West African region and have since ravaged a significant proportion of the population numbering about 7000 (WHO, 2014b)

The quick response of the health sector in human and material resources at the onset of the discovery of the virus stemmed down its spread thereby limiting its consequential mortality and fatality reduced to less than 40 percent of the infected persons. Data indicates that most Nigerians represented by the sample got the information about EVD when it was reported two years ago in West African region. However, only 122 respondents have seen EVD persons in places such as facebook, television and hospitals.

\subsection{Knowledge of Transmission Routes}

The contiguity of EVD and the consequential manifestations on its spread call for an all-inclusive investigation into whether people are well-informed about the transmission routes or not. It was considered necessary to place respondents in this study on different variables associated with the spread of EVD to ascertain their extent of knowledge and behavioural responses in case they had physical contact. These variables ranged from physical contact and behaviour that can enhance and facilitate body fluid contact and transmission from person to person. Over four-fifths believed that kissing an EVD infected person will spread the virus, physical touching (90.3\%), sexual relationship (86.1\%), hugging $(85.2 \%)$, handshake $(87.1 \%)$, dancing together $(64.2 \%)$ and sleeping on the same bed $(81.6 \%)$. Most of the EVD transmission routes are culminated in social interaction such as exchange of pleasantries, sexual behaviour and ceremonies. The data discussed above and presented in Table 3 below are highly suggestive of adequate knowledge about the knowledge of the spread of EVD among the respondents. 
Table 3: Knowledge of Transmission Routes

\begin{tabular}{|l|c|c|}
\hline Responses & Yes f(\%) & No f(\%) \\
\hline Kissing & $248(80)$ & $62(20.0)$ \\
\hline Physical touching & $280(90.3)$ & $30(09.7)$ \\
\hline Sexual relationship & $267(86.1)$ & $43(13.9)$ \\
\hline Hugging & $264(85.2)$ & $46(14.8)$ \\
\hline Handshake & $270(87.1)$ & $40(12.9)$ \\
\hline Dancing together & $199(64.2)$ & $111(35.8)$ \\
\hline Sleeping on the same bed & $253(81.6)$ & $57(18.4)$ \\
\hline
\end{tabular}

Source: Author's Field Survey, 2015

The success story recorded by the Federal Ministry of Health, on stemming the spread of Ebola in Nigeria in 2014 can be justified, to a large extent, on the adequate knowledge about its spread by the Nigerian population. Since most of transmission routes of EVD are largely behavioural, the pattern of interaction among the people in a society goes a long way to influencing the nature and pattern of its spread. The disparities between knowledge, attitude, and practice regarding morbidity and social epidemiology with a rider that at times people's knowledge about the transmission routes of an infection may not have overbearing effects on their attitudes and behavioural practices related to the infection.

\subsection{Knowledge of Symptoms of EVD}

Each disease manifests in various opportunistic infections which can either be symptomatic or asymptomatic. EVD manifest in various symptoms at the onset and at its progression. Knowledge and familiarity with symptoms of a disease influence health seeking behavior and the efficacy of the health system response. Various symptoms were identified as symptoms of infection with Ebola virus and respondents were placed on the level of knowledge about them. The checklist of EVD available on the website of the world health organization (www.who.org) indicate the symptoms of EVD at its onset, progress and fatality to include tiredness of the body $(92.6 \%)$, fever $(93.5 \%)$, weakness of the body $(94.2 \%)$, joint pain $(83.5 \%)$, malaria $(75 \%)$, cough $(79.0 \%)$, Diarrhoea $(82.3 \%)$, vomiting $(87.7 \%), \&$ cholera $(12.3 \%)$ when placed on responses from the sample in this study.

Table 4: Knowledge of EVD Symptoms

\begin{tabular}{|l|c|c|}
\hline Responses & Yes $\mathrm{f}(\%)$ & No $\mathrm{f}(\%)$ \\
\hline Tiredness & $287(92.6)$ & $23(7.4)$ \\
\hline Fever & $290(93.5)$ & $20(7.4)$ \\
\hline Weakness & $292(94.2)$ & $18(5.8)$ \\
\hline Joint pain & $259(83.5)$ & $51(16.5)$ \\
\hline Malaria & $233(75.2)$ & $77(24.8)$ \\
\hline Cough & $245(79.0)$ & $65(21.0)$ \\
\hline Diarrhoea & $255(82.3)$ & $55(17.7)$ \\
\hline Vomiting & $272(87.7)$ & $38(12.3)$ \\
\hline Cholera & $38(12.3)$ & $227(87.7)$ \\
\hline
\end{tabular}

Source: Author's Field Survey, 2015

\subsection{Human Host of EVD}

The host of a virus in human body is one of the major determinants of the pattern of diagnosis, transmission and the vulnerability from one person to another. On dead bodies, $88 \%$ of respondents indicated that and mishandling and mismanagement of dead bodies of infected persons have been identified as one of the potential routes of EVD transmission. In places where people have died of EVD, direct contacts with the dead, occasioned by traditional burial rites, rituals and ceremonies have reportedly increased the infection rate and its associated fatalities.

In situations where the breadwinner of the family dies of spiritually questionable ailment, widows are made to drink the water used to wash the dead bodies. Those who washed the corpse and those who drank of the water stand higher 
risk of infection, if the person died of EVD. Questions were asked from the selected respondents on their level of knowledge about the specifics hosts of EVD in human body. Responses show that though there are variations, but the pattern of responses indicates a pattern of dimension. Respondents indicate that the following body fluids are believed to be major hosts of EVD; saliva (79.7\%), faeces (71.6\%), semen (70.3\%),Breast milk (72.6\%), Tears (64.2\%), blood $(81.6 \%)$.

Table 5: Human Host of EVD

\begin{tabular}{|l|c|c|}
\hline Responses & Yes f(\%) & No f(\%) \\
\hline Saliva & $247(79.70)$ & $63(20.3)$ \\
\hline Faeces & $222(71.6)$ & $88(28.4)$ \\
\hline Semen & $218(70.3)$ & $92(29.7)$ \\
\hline Breast milk & $225(72.6)$ & $85(27.4)$ \\
\hline Tears & $199(64.2)$ & $111(35.8)$ \\
\hline Blood & $253(81.6)$ & $57(18.4)$ \\
\hline
\end{tabular}

Source: Author's Field Survey, 2015

\subsection{EVD \& Animals Host}

The wide public health education given to EVD at its outbreak in the West African sub-region, most especially as it relates to the spread through animals. Respondents were asked to place different animals on EVD infection and their ability to transmit to humans. The general trend of responses shows that greater proportion will avoid eating bush meat for the fear of contracting the virus. Various scientific reports have indicated that the recent outbreak in Sierra Leone, Guinea and Liberia are traceable to fruits bats contacts with humans. Generally, over $70 \%$ indicated that all animals on the list will host and transmit EVD; Fruit bats (74.8\%), Normal bats (75.5\%), Monkeys (81.9\%), Chimpanzee $(73.2 \%)$. A proportion of the respondents claimed ignorant of whether these set of animals can aid EVD transmission: vulture (49.4\%), chicken $(62.0 \%)$, Beaver (55.2\%). All these animals are common in the forest regions of the West African including Nigeria, they migrate seasonally and are greatly limited by local hunters for consumption.

Table 6: EVD \& Animal Host

\begin{tabular}{|l|c|r|}
\hline Responses & Yes f(\%) & No f(\%) \\
\hline Fruits bats & $232(74.8)$ & $78(25.2)$ \\
\hline Normal bats & $234(75.5)$ & $76(24.5)$ \\
\hline Monkey & $254(81.9)$ & $56(18.1)$ \\
\hline Chimpanzee & $227(73.2)$ & $83(26.8)$ \\
\hline
\end{tabular}

Source: Author's Field Survey, 2015

\subsection{Incubation Period}

Scientifically, EVD has been confirmed to incubate in its host between $2-21$ days. Sample in this study demonstrate a little knowledge about the incubation period. About half (51.3\%) indicated that EVD will remain in human body between 10 - 30 days before it begins to manifest in opportunistic infections.

\subsection{Ebola Therapy}

At the onset of EVD in West Africa, and the devastating effects on the health and wellness of those infected, several attempts were made by Medical Scientists alike towards discovering a cure for the deadly disease. With World Health Organisation taking a lead, other stakeholders in population health have made significant efforts. At the moment, some vaccine trials are taking place in areas of high EVD morbidity and mortality. Scientific effects on human in short and long term are currently being collated. 


\subsubsection{Bitter-Kola EVD Cure therapy}

Suddenly, at the discovery of EVD in Nigeria in 2014 and the subsequent morbidity and death of about seven (7) persons, came the theory of Bitter-kola as curative measures. There was a wide spread information in social media that the intake of certain quantity of bitter-kola can lessen the burden of the virus on human and consequently reduce the morbidity and mortality rising from its infection.

This rose from a suspicion that "Nanosilver" which was imported into the country on the $15^{\text {th }}$ August 2014 was produced using bitter kola. This happened amidst speculations that the Bitter-Kola could offer curative measure for EVD. However, the speculations of the possibility of Bitter Kola offering some relief on the cure of EVD, was cleared by Prof. Maurice Iwu (Azuzu, 2014).

He claimed that in a Research Team, established around 1985 in the US, "our team then screened so many compounds. About 2,000 compounds against viruses which seem to have no treatment were screened and Ebola was among. We were lucky that a compound from Garcinia kola which is Bitter kola was able to arrest the replication of the Ebola virus. It was not a cure but that was a big clue". Professor Iwu had, in article published in 1999, established that Garcinina Kola had a compound which could stop the replication of the Ebola Virus (www.premiumtimesng.com). According to him, Garcinina Kola was used to stem the rate of EVD spread in Kikwit, a Province in Congo for a period of five years before new cases resurfaced.

Table 7: Bitter-Kola EVD Cure Therapy

\begin{tabular}{|l|c|c|}
\hline Responses & Yes f(\%) & No f(\%) \\
\hline Ate bitter kola & $156(50.3)$ & $154(49.7)$ \\
\hline Frequency of bitter-kola consumption & $231(74.5)$ & $79(25.5)$ \\
\hline Bitter-kola is medicinal & $245(79.0)$ & $65(21.0)$ \\
\hline Bitter-kola can prevent and cure Ebola & $211(68.1)$ & $99(31.9)$ \\
\hline Bitter-kola reduces Ebola viral load & $56(18.1)$ & $254(81.9)$ \\
\hline
\end{tabular}

Source: Author's Field Survey, 2015

Bitter Kola is widely grown in the forest region of South-Western Nigeria. As a precautionary measure, though not scientifically confirmed, about $53 \%$ of the respondents ate bitter-kola as preventive measures while the remaining $47 \%$ ate ordinary kola. Also, about $74.5 \%$ of those who ever ate bitter kola consumed it frequently out of which $78.4 \%$ confirmed that bitter kola was medicinal and could contribute positively to human health and wellness. On whether it can prevent and cure Ebola, greater proportion (68\%) argued that the potential to prevent infection with Ebola virus if it was eaten within six (6) hours prior to contact while the remaining $32 \%$ could not confirm this. Open ended responses from these respondents indicated that they increased the level of consumption of bitter Kola during the time EVD was reported in Nigeria and the unit price of Bitter Kola skyrocketed up to about $150 \%$ increase.

According to this category of respondents, bitter kola contains some chemical elements which they believe could prevent the intrusion of certain viruses in the human body. However, among those who believed in preventive theory, just $18 \%$ indicated that consuming more quantities of bitter-kola could render the virus in an already infected body, inactive by strengthening the immunity and ability of the body defence mechanism to fight the virus.

\subsection{The Midnight-Salted-Water EVD Preventive Magical Therapy}

While the Nigerian health system was battling with the morbidity and mortality arising from EVD in 2014, information circulated online on social media that bathing with salt water could prevent infection with EVD. The information specifically indicated that Nigerians should, in the mid-night, bath with salted-water to prevent infection with EVD.

Consequent upon the threat from the dreaded EVD which the government declared a national emergency in 2014, Nigerians scrambled for salt-water soap-less bath as magical prescription for the prevention as allegedly recommended by the traditional ruler of the Igala Kingdom, the Attah of Igala who prescribed salt-water solution as a magical vaccine against the virus. The prescription went viral on social media and text messaging platforms which spread faster to almost all parts of Nigeria. There were also reports that a Catholic priest, EjikeMbaka, also asked his followers to perform some religious rituals which included drinking salt water as preventive measure (www.nigerianmonitor.com)

In this study, respondents were asked about their belief on the efficacy of the magical vaccine and whether they 
administered it for preventive reason. Data showed that almost all the respondents $(98.7 \%)$ reportedly consumed salt in food while just $1.3 \%$ reportedly did not consume salt for medical reasons. Out of those who reportedly consumed salt, $78.8 \%$ took salt regularly in food on daily basis while the remaining $21.2 \%$ did not. Regular intake of salt at abnormal quantity often results in some health hazards which threaten human's health and wellness. On whether respondents ever bathed with salt water, $86.5 \%$ reported that they bathed with salt water as preventive measure against EVD. During the circulation of information via short message service and other social media, suggesting the possibility of salt water bath as therapeutic against infection with EVD, these respondents reportedly bathed with salt water at mid-night as preventive measure. About four-fifth of the total respondents got and believed in the efficacy of the salt water therapy, out of which $98 \%$ actually bathed with salt water at midnight.

Table 8: Mid-night Salt-water therapy

\begin{tabular}{|l|c|c|}
\hline Responses & Yes f(\%) & No f(\%) \\
\hline Salt consumption & $305(98.4)$ & $5(1.6)$ \\
\hline Regular salt consumption & $245(79.0)$ & $65(21.0)$ \\
\hline Bathed with salted water & $302(97.4)$ & $08(2.6)$ \\
\hline
\end{tabular}

Source: Author's Field Survey, 2015

\section{Conclusion and Recommendations}

The developmental challenges of most of the economies of West African countries, Nigeria inclusive, have always made the provision of health infrastructures inadequate to meeting the needs of population health. The situation is worsened by the increasing incidence of highly contagious diseases which are deadly. The re-occurrence of EVD and its consequences on human health leading to a considerable death could be linked to the unpreparedness of the existing health care system.

The EVD situation in Nigeria, though curtailed early enough should not be celebrated, but certain precaution and measures such as improved personal hygiene, improvement on the health infrastructures, training of medical personnel and good environmental health practices should be put in place to forestall the re-occurrence of the viral infection. Further research should be conducted on the socio-cultural, medical and science of EVD.

\section{References}

Althaus, C. L. (2014). Estimating the reproduction number of Ebola virus (EBOV) during the 2014 outbreak in West Africa.PLoSCurr, (6) $22-535$

Azuzu Michael (2014) 'War against the Ebola Virus Disease in Nigeria: counting our successes and scaling up on it. (Being an invited key note address at the NMA National \& Abuja FCT Branch Week Opening Ceremony, 21/10/14)

WHO Ebola Response Team (2014b).Ebola virus disease in West Africa-the first 9 months of the epidemic and forward projections. North England Journal of Medicine, 371(16):1481-95.

Fasina, F., Shittu, A., Lazarus, D., Tomori, O., Simonsen, L., Viboud, C., and Chowell, G. (2014).Transmission dynamics and control of Ebola virus disease outbreak in Nigeria, July to September 2014. Euro Surveill, 19(40): 14 - 22

Nishiura, H. and Chowell, G. (2014).Early transmission dynamics of Ebola virus disease (EVD), West Africa, March to August 2014.Euro Surveill, 19:36.

http://www.m.allafrica.com

http://www.en.wikipedia.org

http://www.nigerianmonitor.com/2014/08/15/ebola-in-nigeria-read-five-latest-news-updates-about-ebola-virus/

http://www.nigerianmonitor.com/2014/08/15/ebola-in-nigeria-read-five-latest-news-updates-about-ebola-virus/

http://www.vanguardngr.com/2014/08/bitter-kola-cure-ebola-virus-iwu/

http://www.premiumtimesng.com/news/166257-ebola-sparks-panic-across-nigeria-as-citizens-scramble-for-salt-water-bath-remedy.html http://www.who.int/csr/don/2014_08_08_ebola/en/

(http://ec.europa.eu/echo)

CDC Ebola site: www.cdc.gov/ebola CDC Travelers' Health site: http://wwwnc.cdc.gov/travel/notices World Health Organization (WHO) Ebola virus disease (EVD) site: www.who.int/csr/disease/ebola/en/

http://www.who.int/mediacentre/news/ebola/20-october-2014/en/. World Health Organization (2014d). The outbreak of Ebola virus disease in Senegal is over.

Citation style for this article: Fasina FO, Shittu A, Lazarus D, Tomori O, Simonsen L, Viboud C, Chowell G. Transmission dynamics and control of Ebola virus disease outbreak in Nigeria, July to September 2014. Euro Surveill. 2014;19(40):pii=20920. Available online: http://www.eurosurveillance.org 